CASE REPORT

\title{
Management of Residual Pituitary Adenoma Patient with Manifestation of Acromegaly and Hyperprolactinemia
}

\author{
Khoirotul Ummah ${ }^{1}$, Soebagijo Adi ${ }^{2 *(1)}$ \\ ${ }^{1}$ Department of Internal Medicine, Faculty of Medicine, Universitas Airlangga - Dr. Soetomo General \\ Academic Hospital, Surabaya, Indonesia
}

${ }^{2}$ Division of Endocrin and Metabolic Diabetes, Department of Internal Medicine, Faculty of Medicine - Dr. Soetomo General

Academic Hospital, Surabaya, Indonesia

\begin{abstract}
A B S T RA C T
Pituitary adenoma is one of intracranial tumors that grows and develops in the pituitary gland which plays a role in regulating the hormonal balance in the body. Most pituitary adenomas are benign and do not spread to other organs. Pituitary adenoma can be classified based on radiological features, tumor size and the type of hormone produced. There are several ways to establish of diagnosis of pituitary adenoma, in addition to recognizing the symptoms and clinical signs are hormonal function tests and imaging. The surgery is the first medical actions. The postoperative recovery rate reached $90 \%$ in relatively benign cases and tumor recurrence rate is $5-10 \%$ depending on the size of the tumor, the stage of the tumor during surgery, experience of neurosurgical. A woman, 46 years old referred to Dr Soetomo General Academic Hospital from Soebandi Jember Hospital for treatment the recurrent adenoma pituitary with complains of headache, double-vision and changing shape of his face, his enlarged lips and nose. Patient was diagnosed based on head CT scan and already had surgery on January, 2015. The head MRI evaluated post surgery was still a residual mass from the previous tumor. Three months after surgery no complains any more. The complains reappear at the end of 2017. The head CT scan on January, 8, 2017, size tumor: $1.2 \mathrm{~cm} \mathrm{x} 1.8 \mathrm{~cm}$. The head MRI results on December, 20,2017 size tumor : size $1.6 \mathrm{~cm}$ x 2.1 cm and abnormal hormonal result, high prolactine, low cortisol and high IGF1. In Dr Soetomo General Academic Hospital was diagnosed as pituitary macroadenoma with acromegaly and hyperprolactinemia and received bromocriptine $3 \times 5 \mathrm{mg}$ evaluated for 2 weeks then lowered to $3 \mathrm{x}$ $2.5 \mathrm{mg}$ after obtaining a decrease in prolactin levels and methyl prednisolone $3 \times 1$ /day until cortisol level was normal. Patients will also plan for surgery of EETH (Endoscopic Endonasal Transphenoidal).
\end{abstract}

Keywords: Pituitary adenoma, Hyperprolactinemia, Acromegaly, Endoscopic endonasal transphenoidal

Correspondence: Soebagijo Adi

E-mail: soebagijo.adi.s@fk.unair.ac.id

Article history: •Received 16 December $2020 \bullet$ Received in revised form 21 January $2021 \bullet$ Accepted 11 February 2021

\section{INTRODUCTION}

Pituitary adenoma is a benign tumor that develops in the pituitary gland, the part of the brain responsible for regulating the hormonal balance in the body, plays a role in regulating growth hormone and some other important hormones that regulate the function of the thyroid gland, adrenal glands, gonadal glands and lactation control. This pituitary adenoma causes a change in hormone production in the pituitary gland, causing too much or too little of the hormone to affect body function. This adenoma grows confined to the pituitary gland or surrounding tissue and does not spread to other parts of the body (Lake et al., 2013).

About $10 \%-15 \%$ of all intracranial tumors are pituitary tumors, making it the third most brain tumor after glioma and meningioma. Epidemiological data in the United States shows that the incidence of this case has a range of 0.4 to $18.7 / 100.000$ population. The width of this incidence range is due to the nature of this tumor which is generally asymptomatic.
This pituitary adenoma is primarily about the age of 20-50 years, with a balanced incidence in males and females (Philips, 2013). Most pituitary tumors are found in adults of about $10 \%$ to $25 \%$ of intracranial neoplasms but can also be found at the age of children and adolescents (Chanson and Salenave, 2004).

The surgery is the first line of medical action. The postoperative recovery rate reached $90 \%$ in relatively benign cases. The tumor recurrence rate is $5-10 \%$ depending on the size of the tumor, the stage of the tumor during surgery, experience of neurosurgical (Laws et al., 2014). The surgical technique currently employed in Indonesia is transfenoid per endoscopy. This procedure is performed using an endoscope that is inserted through the nose and sinus to reach the bottom of the brain without an external incision and leaving no visible scars. The technique has an advantage in field surgery visualization as well as lower morbidity rate per microscopic technique (Dallapiazza et al., 2015). 
This paper will discuss the management of residual pituitary adenoma with hyperprolactinemia and acromegaly manifestations. In the case of the residif indicates some problems related to the selection of therapy. The most important thing to note is a strict follow-up to the possibility of recurrence of recurrence of the tumor.

\section{CASE REPORT}

A woman, Mrs. Mf, 46th, housewife, Javanese, and resident in Jember, came to Dr Soetomo General Academic Hospital referral from neurosurgeon of Soebandi Jember Hospital. The patient was referred to $\mathrm{Dr}$ Soetomo General Academi Hospital of neurosurgery for treatment of recurrent pituitary adenoma. The patient was diagnosed as pituitary adenoma in January 2015.

Her chief's complain was often headache and double vision since early January 2015. Her complaints are not accompanied by a sense of fever, nausea, vomiting or spinning head. Patients have no history of using minus or plus glasses. In addition, patients also complain of changes in the hands, feet and face shape. Patients feel the size of hands and feet larger than the original, so that the rings and shoes are commonly worn no longer fit. The patient also complained about the changing shape of his face, his enlarged lips and nose. Menstruation is also felt irregularly, but patients are not using contraception. A few months later, headache and double vision got worse, even the patient had fainted because of headache. So the patient decided to seek medical eye doctor. A number of checks have been done by an ophthalmologist, and the results show that the patient had severe field disturbance. So the patient is given a referral to examine the CT scan of the head with contrast. The results was a pituitary tumor (adenoma) in the patient (CT scan of the head on 8 January 2018). Then by an ophthalmologist, the patient was referred to a neurosurgeon at Soebandi Hospital in Jember. Based on the results of an examination by a neurosurgeon at Soebandi Hospital in Jember, the patient was adjudged for an operational action plan (January, 22, 2015). After surgery, the patient re-evaluated her adenoma condition via head-up MRI (January 30, 2015), and the result was still a residual mass from the previous tumor. After the surgery, patient still control to a neurosurgery doctor until 3 first month because there is still a complaint headache. After 3 months post operation, the patient has no more complaints so the patient does not come control to the doctor. But headache is felt again by the patient at the end of 2017, then the patient performed MRI repeated with the results of the remaining tumor relatively larger size and from laboratory examination there is high prolactin hormone results, so patient referred to the neurosurgery of Dr Soetomo General Academic Hospital. Patient no history of Diabetes, hypertention or heart disease.

Physical examination on January 3, 2018, She was alert, compos mentis, general condition enough, blood pressure
120/70 mmhg, pulse 82 times/minute, temperature 36.8 celcius and breathing 18 times/minute. Head examination is not found anemis, jaundice, cyanosis or tightness. On neck examination did not get enlarged neck gland. On examination of the chest region there was symmetrical breathing, no respiratory muscle retraction, no murmurs, and no gallops. In both lung fields there was a vesicular breath sound, neither ronki, nor wheezing. On abdominal examination obtained normal bowel sounds, liver and lien in normal limits. On examination of the extremity obtained akral warm, dry, the bones of hands and feet enlarged.

Laboratory examination on December 9, 2017: GH 18.5, TSHs 1.27, FT3 2.22, Ft4 0.730, prolactin 33.96, cortisol 4.23. Hemoglobine $11.3 \mathrm{~mm} / \mathrm{dl}$, leucocyte $5.67 / \mathrm{mm} 3$, thrombocyte $417.000 / \mathrm{mm} 3$. The head CT scan on Januri, 8, 2017 before surgery showed a mass of itrasella that began to extend into the cavernosus sinus, sphenoid sinuses and ethmoid measuring $1.2 \mathrm{~cm} \mathrm{x} 1.8 \mathrm{~cm}$. The head MRI results on December 20, 2017 showed lobulated-shaped mass of firm borders, the irregular edge of intracellar urgent posterior left sphenoid wall (size $1.6 \mathrm{~cm} \times 2.1 \mathrm{~cm}$ ). Thorax photo examination in normal limit.

Patients was diagnosed as pituitary macroadenoma with abnormalities of acromegaly hyperprolactinemia and hypocortisol. Patients was planned Endoscopic Endonasal Transphenoidal (EETH) by Soetomo's neurosurgeon and received bromocriptine $3 \times 5 \mathrm{mg} /$ day and methyl prednisolone $3 \times 1 /$ day.

\section{Disease Progression}

Second visit Endocrine poly, the patients with complaints headache and view felt sandy. Vital sign examination are good, blood pressure 120/80 mmhg, pulse 84 times/min, respiratory rate 20 times/min, laboratory testosterone 24.85 , cortisol 9.63, Hb 12.7, leukocytes 5830/ul, plt 323.000, GDP 105, Gd 2jpp 115, SGOT 20U/L, SGPT 27 U/L, BUN 10, SK 0.5, Na 142, K 4.5, Clorida 111, calcium 9.2. T SH 0.948, FSH 1.67, LH 0.49 ACTH 12.6, cortisol 9.63. Patients received bromocropine $3 \times 5 \mathrm{mg}$ /day.

The third visit of Endocrine Poly, the patients with slight headache and sandy outlook showed that the vital sign was good, blood pressure 110/80, pulse 80 times/min, respiratory rate $18 \mathrm{times} / \mathrm{min}$, the results of laboratory test prolactin was 13.38, cortisol 9.42, TSH 0.713, FT4 0, 76, LH 0.6, FSH 0.86. Patients will be planned to examine insulin-like Growth Factor 1 (IGF-1) and Thyroid Ultrasonography. Patients received bromocriptine therapy $3 \times 2.5 \mathrm{mg} / \mathrm{hr}$.

The fourth visit of Endocrine Poly, the patients with headache were not found and the view was still sandy, vital sign examination was good, blood pressure 120/80 mmhg, pulse 80 times/min, respiratory rate 20 times/min, laboratory test result Hemoglobine 12, Leukocytes 6.48, neutrofil 49. $2 \%$, platelet 344,000, K 4.3, Na 141, Cl 107, Ca 9.1, 
prolactin 3.36, GH 17.1, cortisol 9.90. IGF-1 $695 \mathrm{ng} / \mathrm{ml}$ (N: 74-196), GDP 110, Gd2jpp 101, Bun 9, creatinine serum 0.7, total cholesterol 267, Triglyceride 232, HDL 29, LDL 175. Patients received bromocriptine $1 \times 2.5 \mathrm{mg} /$ day, atorvastatin $20 \mathrm{mg}$.

The fifth visit of Endocrine Poly, the patients with sandy outlook complaints with vital sign examination are good, blood presure $110 / 80 \mathrm{mmhg}$, pulse $82 \mathrm{x} / \mathrm{m}$, respiratory rates 18 times/min with laboratory test results of GDP 105, Gd2jPP 155, TSH 0,557, FT4 0.66, prolactin 15,33, cortisol 5.8, Thyroid ultrasound bilateral thyroid cyst, colloid thyroid nodule left. Patients received bromocriptine therapy $1 \mathrm{x}$ $2.5 \mathrm{mg} /$ day. The patient is waiting for a call for EETH surgery.

\section{DISCUSSION}

Pituitary Tumor is a tumor that grows and develops in the pituitary gland. The pituitary gland lies in sella tursica, at the base of the skull. It called the master gland, which plays a role in regulating growth hormone and some other important hormones that regulate the function of the thyroid gland, adrenal glands, gonadal glands and lactation control. This pituitary gland consists of two lobes, the anterior lobe (adenohipofisa) and the posterior lobe (neurohipofisis). The anterior lobe produces five peptide hormones: prolactin hormone, growth hormone (Growth Hormone), glycoprotein hormone; Luteinezing Hormone (LH) and Stimulating Hormone Follicle (FSH), Thyroid stimulating hormone (TSH) hormone and Adrenocorticotropic hormone (ACTH), while the posterior lobe produces two hormones: oxytosis and vasopressin (Arafah and Nasrallah, 2011).

Most pituitary adenomas are benign and do not spread to other organs. Prevalence between women and men is no different, but most pituitary tumors are found in adults of about $10 \%$ to $25 \%$ of intracranial neoplasms but can also be found at the age of children and adolescents (Chanson and Salenave, 2004).

The pathogenesis of pituitary adenoma isn't certain known, but until the last decade there are two theories applicable to the origin of the tumor. The most commonly accepted theory is that this tumor is an intrinsic abnormality in the pituitary gland itself. Other theories are caused by the hypothalamus. According to the second hypothesis that pituitary tumors are the result of continued stimulation by hormones or hypothalamic factors. Some other opinions mentioned that the emergence of pituitary tumors is caused by the genetic defect of the presence of genes that trigger the occurrence of neoplasia that is multiple endocrine neoplasia type 1 (MEN I) which is a dominant autosomal disorder that shows the incidence obtained from malignant neoplasm and benign ones involving the pituitary gland, the parathyroid gland and the ancreas (Freda and Wardlaw, 2010).
Pituitary tumors can be classified based on radiological features, tumor size and the type of hormone produced. Based on the radiological features it consists of Grade 0: adenoma is not seen radiologically, 2. Grade I and II: limited adenoma in sella turcica 3. Grade III and IV: adenoma that invade into surrounding tissue. Based on the size of the adenoma is divided as: A. Microadenoma : size less than 1 $\mathrm{cm}$, the location is always still in sella turcica and have not invaded surrounding structures such as sphenoid and sinus cavernosus, often when diagnosis is made of, tumor size $50 \%$ $<5 \mathrm{~mm}$ B. Makroadenoma: Size more than $1 \mathrm{~cm}$, usually extends from sella turcica and already invaded surrounding structures, was found because of the compression efect of the tumor, such as bitemporal hemianoption, in addition to endocrine disorders, may be hyper or hyposecretion. Based on hormones produced pituitary adenomas consists of 1 . Non-functional pituitary adenoma (not producing hormones) $25 \%$ of pituitary adenoma 2 . Functional pituitary adenoma (hormone production) of $70 \%$ of pituitary adenoma consisting of: a. prolactin-secreted adenomas (52\%) b. adenoma secreted growth hormone $(\mathrm{GH}) 27 \%$, c. adrenocorticotropic hormone (ACTH) 20\% and d. adenoma secreted TSH 0.3\% (Chanson et al., 2015; Olsson, 2014).

In these patients based on the classification of the tumor, it can be categorized as adenoma of grade 3-4, functional pituitary macroadenoma with hyperprolactinemia and acromegaly manifestations. This patient had a tumor size greater than $1 \mathrm{~cm}$ accompanied by an increase in prolactin hormone production and an increase in insulin-like growth factor 1 (IGF 1).

There are several ways to establish of diagnosis of pituitary adenoma, in addition to recognizing the symptoms and clinical signs are 1. Hormonal function tests to measure hormone levels. This test is required for each patient with a pituitary tumor. Hormone tests can detect or confirm functional adenomas, as well as determine if there is evidence of pituitary insufficiency. Some functional tumors, especially prolactinomas, can be effectively treated without surgery and therefore, it is imperative that a comprehensive hormone test be performed before consideration of surgical removal of the tumor. 2. Imaging, one of the imaging methods used to detect pituitary adenomas is magnetic resonance imaging (MRI) scans. MRI is believed to detect adenomas larger than four millimeters. MRI is preferred for detecting pituitary adenomas, in addition computed tomography (CT) scans can also be used (Bergsneider, 2011; Laws et al., 2013).

In these patients there are frequent complaints of headache and double vision which is felt since early January 2015, the patient also felt a change in the size of his hands and feet are larger than the original. The patient also complained about the changing shape of his face, his enlarged lips and nose. 
In this patient have performed several examinations that support the direction of pituitary tumor is the examination of growth hormone $(\mathrm{GH})$, thyroid hormone (TSH), hormone levels prolactin and cortisol levels. Obtained some results of disruption in hormone production of prolactin hormone increased 33.96 and decreased levels of cortisol 4.23. A CT scan of 8 Januri 2017 before surgery showed a mass of diitrasella that began to expand into the cavernosus sinus, shenonoid sinuses and ethmoid measuring $1.2 \mathrm{~cm} \times 1.8 \mathrm{~cm}$. Head MRI results dated December 20, 2017 post operative mass visible lobulated shape of firm borders, irregular edges on intrasella that push the left posterior right sphenoid wall (size $1.6 \mathrm{~cm} \times 2.1 \mathrm{~cm})$.

Patients with pituitary adenoma showed a variety of clinical signs and symptoms that can be categorized as follows: 1 . Signs and symptoms associated with excessive or defisiency hormone production, such as hyperprolactinemia in patients secreting the hormone prolactin, therefore an endocrine evaluation is required to confirm the presence or or at least endocrinopathy in patients 2 . Signs and symptoms associated with mechanical effects of tumor expansion such as headache symptoms, visual disturbances and cranial nerve palsies (Katznelson et al., 2014).

Prolaktinoma is a prolactin hormone producing pituitary adenoma. Prolactinoma is the most common type of hyperprolactinemia-related pituitary adenoma. Hyperprolactinemia is a state of elevated serum prolactin level exceeding $25 \mathrm{ng} / \mathrm{ml}$ in basal conditions. The normal value of serum prolactin is $5-25 \mathrm{ng} / \mathrm{ml}$; lower in men and children. Prolactin levels in nonpregnant women were less than 20 $\mathrm{ng} / \mathrm{ml}$ and prolactin levels in men were less than $15 \mathrm{ng} / \mathrm{ml}$. Prolactin had daily variation increased at night, maximum at 01.00-06.00 in the morning. Increased levels of prolactin often cause various reproductive system disorders. Menstrual disorders arise due to hyperprolactinemia block the hypothalamus-pituitary ovarial axis in hypotalamus, resulting in decreased secretion of FSH and LH. Decreased secretion of FSH and LH interfere with the process of folikulogenesis, so that estrogen secretion decreases. A low estrogen causes LH surge does not occur, so ovulation does not occur. Hyperprolactinemia can also be found in certain conditions, eg pregnancy, stress, hypoglycemia, renal failure, hypothyroidism and drugs: sedatives: trifluoperazine, haloperidol, and metoclopramide. Symptoms of hyperprolactinemia in women may be amenorrhea, oligomenore, galactorrhea, infertility, osteoporosis, headache, visual disturbances, and signs of elevated androgen levels in women. In men, it is usually asymptomatic but may lead to symptoms of gyneconomic impotence, decreased libido and sexual potency in men (Ajmal et al., 2014).

In these patients were found frequent complaints of headache, double vision and menstrual disorders experienced since early 2015 and prolactin levels obtained 33.96 .
Another manifestation of pituitary adenoma is growth hormone hypersecretion (growth hormone), which, if it occurs in children whose epipheseal has not closed, is called to gigantism and if it occurs in adulthood is called acromegaly. Acromegaly is a disorder that arises from excess growth hormone resulting in excessive growth in various tissues of the body, muscles, and bones, especially in the legs and hands. The incidence of acromegaly in both men and women occurs equally, usually in the fifth decade (Katznelson et al., 2014; Iuliano and Laws, 2013).

Symptoms arise gradually because of the influence of elevated levels of $\mathrm{GH}$ in chronic. Most new sufferers find themselves stricken with Akromegaly after years. Early symptoms include shoe size and enlarged shirt, then visceromegaly, Skin tags, changes in the cuticle and subcutaneous tissue slow fibrous hyperplasia found primarily in the fingers, lips, ears and tongue (Katznelson et al., 2014; Chanson et al., 2009).

Growth hormone is produced and secreted from somatotropic cells in the anterior pituitary lobe. The presence of $\mathrm{GH}$ in the circulation triggers the liver in producing insulin like growth factor I (IGF-1). Insulin-like growth factor (IGF), formerly called somatomedin, is one of several peptide hormones that work primarily to stimulate growth but also has the ability to lower blood glucose levels. IGFs were discovered when researchers began studying the effects of biological substances on cells and tissues outside the body. IGF 1 has effects like insulin in some tissues, although they are much less powerful than insulin in reducing blood glucose concentration. IGF-1 is a major mediator of the growth hormone (GH) effect that stimulates systemic body growth, and has an increased growth effect on almost every cell in the body, especially skeletal muscle, cartilage, bone, liver, kidneys, nerves, skin, hematopoietic cells , and lungs. In addition to effects such as insulin, IGF-1 can also regulate cell growth and development, especially in nerve cells, as well as cellular DNA synthesis (Melmed, 2009).

There are two IGF: IGF-1 and IGF-2. Both of these factors, regardless of their similarity in name, can be distinguished in terms of specific actions on the network because they bind and activate different receptors. The main action of IGFs is on cell growth. Indeed, most of the pituitary growth hormone measures are mediated by IGFs, especially IGF-1. Growth hormone stimulates many tissues, especially the liver, to synthesize and secrete IGF-1, which in turn stimulates hypertrophy (increased cell size) and hyperplasia (increased cell count) of most tissues, including bone. Serum concentrations of IGF-1 increased during childhood and peak at puberty, and they declined subsequently (as was the secretion of growth hormone). Children and adults with growth hormone deficiency had low serum IGF-1 concentrations compared with (eg, acromegaly) has increased 
serum IGF-1 concentrations. IGF-2 production is less dependent on growth hormone secretion than IGF-1 production, and IGF-2 is much less important in stimulating linear growth (Mesfro et al., 2004).

Clinical manifestations of IGF 1 disorders, including 1. Dwarfism; is a rare disease characterized by an inability to make or respond to IGF-1 and produce a specific type of growth failure. One such disorder, called Larwar dwarfism, does not respond entirely to the treatment of growth hormone because of the lack of $\mathrm{GH}$ receptors, 2. Acromegaly. Acromegaly is a syndrome that occurs when the anterior pituitary gland produces excess growth hormone $(\mathrm{GH})$. A number of disorders may increase the pituitary GH output, although most often involving a tumor called pituitary adenoma, originating from different cell types (somatotrophs). This leads to changes in anatomy and metabolic dysfunction caused by increased GH and insulin growth rate 1 (IGF-1) (Akin and Yerlikaya, 2011; Molitch et al., 2006).

Measurement of GH levels can not be trusted because of the secretion of this hormone in the form of spark, although in the state of adenoma. Normal basal levels of $\mathrm{GH}<1 \mathrm{ng} / \mathrm{ml}$, in patients with measurements of somatemedin $\mathrm{C}$ levels are more reliable, since their levels are constant and increase in acromegaly. Normal levels of $0.67 \mathrm{U} / \mathrm{ml}$, Acromegaly may increase to $6.8 \mathrm{U} / \mathrm{ml}$ Acromegaly may increase to> $5 \mathrm{ng} / \mathrm{ml}$, although in patients it is usually normal (Melmed, 2009).

In these patients there is a complaint of changes in the hands and feet are enlarged, it is known from the rings and shoes that are usually worn no longer fit. In addition, the patient also complained of enlarged lips and nose, and the jaw bone prominence. Laboratory examination was obtained by the increase of Insulin Like Growth Factor (IGF 1) 1695 $\mathrm{ng} / \mathrm{ml}$ (N: 74-196).

Management of pituitary adenoma should be done comprehensively and individually, with objectives 1 . Overseeing clinical and biochemical signs of excessive hormone secretion, 2 Maintenance of normal function of the pituitary wherever possible, 3. Managing weakness of pituitary function, 4. Monitoring tumor growth and mechanical effect on structure surrounding. There are three modalities of therapy that can be performed in cases of pituitary adenoma, surgery, medical and radiotherapy (Katznelson et al., 2014).

Surgical action is expected to lift the entire mass of the tumor so that control of growth hormone secretion can be achieved. This action becomes an option in patients with complaints arising from tumor compression. . Size of tumor before surgery affects the success rate of therapy. In patients with microadenoma the normalization rate of IGF I reaches $75-95 \%$, while in macroadenoma the hormonal normalization rate is lower at $40-68 \%$. In addition to the size of the tumor, other factors that determine the success of the surgery are the surgeon's experience and hormone levels before surgery (Laws et al., 2014).

The surgical technique currently employed in Indonesia is transfenoid per endoscopy. Transsphenoidal Surgery is a procedure for removal of a pituitary tumor located at the base of the brain that is difficult to reach. This procedure is performed using an endoscope that is inserted through the nose and sinus to reach the bottom of the brain without an external incision and leaving no visible scars. The technique has an advantage in field surgery visualization as well as lower morbidity rate per microscopic technique (Dallapiazza et al., 2015).

Medical therapy in acromegaly consists of three classes, namely dopamine agonists, somatostatin analogues, and growth hormone receptor antagonists. Dopamine agonists consist of bromocriptine and cabergoline. Monotherapy with cabergoline has a efficacy of between $10-35 \%$ in normalizing IGFI levels. In the 64 series of patients with acromegaly treated with cabergoline for 3 to 40 months at a dose of 1.0$1.75 \mathrm{mg} /$ week reduced $\mathrm{GH}$ and IGF I levels in $40 \%$ of patients. Bromocriptine can be used to treat hyperprolactinaemia and also acromegaly. For hyperprolactinemia the initial dose of bromocriptine can be given $1.25 \mathrm{mg}$ or $2.5 \mathrm{mg}$ orally daily with a maintenance dose: $2.5 \mathrm{mg}$ to $15 \mathrm{mg}$ orally daily. For initial doses Acromegaly starts at $2.5 \mathrm{mg}$ with maintenance doses reaching 20-30mg (Arafah and Nasrallah, 2011).

Somatostatin analogues work to resemble somatostatin hormone, it is used to block hormone release in endocrine tumors, incuding inhibiting growth hormone secretion. Native somatostatin reduces symptoms in patients with carcinoid syndrome. However, its use is limited by its short half-life ( $\sim 2$ minutes). With the availability of synthetic somatostatin analogues, octreotide (half-life, 90 minutes) and lanreotide. This group of drugs has an effectiveness of about $70 \%$ in normalizing levels of IGFI and growth hormone. Its high effectiveness makes the somatostatin analog group drug as the first choice in medical therapy. Studies assessing the effectiveness of this class of drugs show that IGFI normalization is achieved in $51 \%$ of subjects after longacting somatostatin analogue for 36 months. In addition to normalizing levels of IGFI, somatostatin analog therapy can also shrink tumor size (80\%), improvement of heart function, blood pressure, and lipid profile. The main problem faced to date is the high cost to be incurred. There are two effective long-acting somatostatin analogue preparations: intramuscular ocreotide long acting release (LAR), and deep sc lanreotide depot/autogel given monthly. The approved initial dose of ocreotide LAR is $20 \mathrm{mg} / \mathrm{month}$ with a dose titration every 3-6 months down to $10 \mathrm{mg}$ or up to 40 $\mathrm{mg} / \mathrm{month}$. Lanreotide autogel/initially approved dose depot 
$90 \mathrm{mg} / \mathrm{month}$ dose is titrated down to $60 \mathrm{mg} / \mathrm{month}$ or up to $120 \mathrm{mg} / \mathrm{month}$ (Calao et al., 2009).

The growth hormone receptor antagonist is a new class in acromegaly medicament therapy. Pegvisomant is an analogous recombinant human growth hormone that acts as a selective GH receptor antagonist. This class of drugs is recommended in cases of acromegaly that can not be controlled with surgical therapy, administration of dopamine agonists, or somatostatin analogues. Pegvisomant was administered subcutaneously at a dose of 10,15 or 20 $\mathrm{mg} /$ day. normalization of IGFI is dose dependent and can be achieved in patients receiving doses up to $40 \mathrm{mg}$ day (Neggers et al., 2011).

Radiotherapy is generally not used as first-line therapy in acromegaly cases but is used as adjuvant therapy for pituitary tumors because of the length of time the effective therapy has been reached since it was first started. The purpose of radiation therapy for pituitary tumors is to reduce or control tumor size. Two types of radiation therapy are used to treat pituitary tumors: 1. Conventional External Beam Radiation 2. Radiosurgery stereotactic. Conventional External Beam Radiation uses fractionation, where treatment is delivered in daily fractions for several weeks. Whereas in stereotactic radiosurgery, the tumor tissue is irradiated with the appropriate dose and conformal volume so that healthy tissue is spared from the effects of radiation (Bergsneider et al., 2016).

In these patients received $3 \times 5 \mathrm{mg}$ of bromocriptine therapy evaluated for 2 weeks then lowered to $3 \times 2.5 \mathrm{mg}$ after obtaining a decrease in prolactin levels from 33.97 to 13.38 . Patients will also plan for surgery of EETH (Endoscopic Endonasal Transphenoidal).

Monitoring of the biochemical response of the therapy was performed by examining growth hormone levels and IGFI. Generally the examination is performed 3-6 months after surgery. Biochemical control is defined as a growth hormone level $<1.0 \mathrm{ng} / \mathrm{ml}$ and normal IGFI levels. Postoperative MRI examinations are generally performed 3-4 months later. In patients undergoing medical therapy MRI examination is performed every 3-4 months after starting therapy (Vincent et al., 2007). Acromegaly is associated with an increased risk of mortality of 2-2.5 times, and normalization of GH or IGFI or both has shown to reduce the risk of mortality. Control of GH and IGFI should be an important focus of therapy for acromegaly, in particular to reduce the risk of mortality (Sherlock et al., 2010).

\section{CONCLUSION}

A case of a female, Mrs. Mf, 46th references to Soebandi Jember Hospital with a diagnosis of residual pituitary macroadenoma with hyperprolactinemia and acromegaly manifestations. The patient was diagnosed as a pituitary macroadenoma based on a CT scan of January 8, 2015 with a headache complaint, a double glance and changes in the hands, legs, facial shape and enlarged jawbone. The patient had undergone tumor surgery on January, 222015 and declared residif based on MRI in December 2017 with a headache and sandy-like outlook so the patient was referred to Soetomo Hospital. There have been several hormonal checks related to this patient's disease. High levels of prolactin and IGF 1 were obtained. Patients received bromocriptine $3 \times 5 \mathrm{mg}$ therapy with evaluation of prolactin hormone levels and planned EETH surgical removal by neurosurgeon. The success rate of surgical therapy depends on the size of the tumor, the stage of the tumor during surgery, the hormone level and the surgeon's experience. Good control of GH and IGF 1 may decrease mortality.

\section{CONFLICT OF INTEREST}

The authors declare there is no conflict of interest.

\section{REFERENCES}

Ajmal A, Joffe H, Nachtigall LB. 2014. Psycotropic-indiced hyperprolactinemia: a clinical review. Psychosomatics. 55(1):29-36.

Akin F and Yerlikaya E. 2011. Acromegaly and Gigantism, Contemporary Aspects of Endocrinology. DiamantiKandarakis E (Ed.). Available from http://www. intechopen.com/books/contemporary-aspects-of-endocrinology/acromegaly-and-gigantism.

Arafah BM and Nasrallah MP. 2011. Pituitary tumors: pathophysiology, clinical, manifestations and management. Endocr Relat Cancer 8(4):287-305.

Bergsneider M, Neil M, Anthony H, Won K, Marilene W, Jeffrey S, Nader P, Tania K, et.al. 2016. Pituitary Tumor Program. Available from http://pituitary.ucla. edu/pituitaryadenomas. Accessed 2 Desember 2016.

Bergsneider. 2011. Radiation therapy in the management of pituitary adenomas. J Clin Endocrinol Metab 96(7):19922003.

Calao A, Auremma RS , Galdiero M, Lombardi Q, Pivonello R. 2009. Effect of initial therapy for five years with somatostatin analoqs for acromegaly on Growth hormone and insulin like growth factor 1 level, tumor shrinkle, cardiovascular disease: aprospective study. J Clin Endocrine Metab 94(10): 3746-3756.

Chanson P, Raverot G, Cortet RC, Salenave S. 2015. Management of clinically non functioning pituitary adenoma. Annals of Endrocrinology 76(3):239-247.

Chanson P, Salenave S, Kamenicky P, Cazabat L, Young J. 2009. Pituitary tumours: acromegaly. Best Pract Res Clin Endocrinol Metab 23(5):555-574.

Chanson P, Salenave S. 2004. Diagnosis and Treatment of Pituitary Adenomas. Minierva endocrinologica 29(4):241275. 
Dallapiazza RF, Grober Y, Starke RM, Laws ER Jr, Jane JA Jr. 2015. Long-term results of endonasal endoscopic transsphenoidal resection of nonfunctioning pituitary macroadenomas. Neurosurgery 76(1): 42-53.

Freda PU and Wardlaw SL. 1999. Diagnosis and treatment of pituitary tumors. The Journal of Clinical Endocrinology and Metabolism 84(11):3859-3866.

Iuliano SL and Laws ER (2013). Recognizing the clinical manifestations of acromegaly: case studies. Journal of the A merican Association of Nurse Practitioners 26(3):136-142.

Katznelson L, Laws ER, Melmed S, Molitch ME, Murad MH, Utz A, Wass JAH. 2014. Acromegaly: an endocrine society clinical practice guideline. The Journal of Clinical Endocrinology and Metabolism 99(11):3933-3951.

Lake MG, Krook LS, Cruz S V. 2013. Pituitary adenomas: an overview. Am Fam Physician 88(5):319-327.

Laws ER, Lanzino G, Elsevier Laws ER, Ezzat S, Asa SL, Rio LM, Michael L, Knutzen R. 2014. Pituitary Disorders Diagnosis and management transsphenoidal surgery. Editors (eds.). London, Wiley-Blackwell; p357.

Sheehan JP, Pouratian N, Steiner L, Laws ER, Vance ML (2013). Gamma knife surgery for pituitary adenomas: factors related to radiological and endocrine outcomes. J Neurosurg 114(2):303-309.

Melmed S. 2009. Acromegaly pathogenesis and treatment. J Clin invest 119(11):3189-3202.
Mesfro A, Webb SM, Astorga R, Benito P, Calala M, Gastambide S. 2004. Epidemiology, clinical characteristics, outcome, morbidity and modality in acromegaly based on the Spanish acromegaly registry. Eur J Endocrinol 151:439-446.

Molitch ME, Clemmons DL, Malozowski S, Merriam GR, Shalet SM, Vance ML. 2006. Evaluation and treatment of adult growth hormone deficiency: an endocrine society clinical practice guideline Journal Clinical Endocrinol Metab 91(5):1621-1634.

Neggers SJ, de Herder WW, Feelders RA, van der Lely AJ. 2011. Convention of daily pegvisomant to weekly pegvisomant combined with long acting somatostatin analogs in controlled acromegaly patients. Pituitary 14(3):253-258.

Olsson DS. 2014. Non functioning pituitary tumours mortality, morbidity and tumour progression. Institute of Medicine at the Sahlgrenska Academy University of Gothenburg.

Phillips N. 2013. The Pituitary MDT. Guidelines for the Management of Pituitary Tumours. Yorkshire, Brain and CNS NSSG, p 25.

Sherlock M, Ayuk J, Tomlinson JW, et al. 2010. Mortality in patients with pituitary disease. Endocr Rev 31(3):301-34.

Vincent M Frederick, Talavera Francisco, Egan Robert, Baker J Matthew, Lorenzo Nicholas. 2007. Pituitary tumors. eMedicine Neurology Neurooncology Journal of Clinical Endocrinology and Metabolism 99(11):3933-51. 